\title{
MODEL VALIDATION FOR A SHROUDED ROTOR-STATOR SYSTEM WITH SUPERPOSED COOLING AND STATIC PROTUBERANCES
}

\author{
Alexander D. W. Pett
}

\author{
Daniel D. Coren \\ Thermo-Fluid Mechanics Research Centre \\ University of Sussex, \\ Falmer, Brighton, BN1 9QT \\ United Kingdom
}

\author{
Peter R. N. Childs
}

\begin{abstract}
This paper analyses numerical and experimental data gathered from a shrouded rotor-stator wheelspace supplied with a radial outflow of cooling air introduced along its central axis. Computational Fluid Dynamics (CFD) investigations into plain disc, roughened disc, roughened stator and stator protrusions were carried out and the results compared to previously gathered experimental data in order to validate the CFD code and improve confidence in its ability to model the given situations.

Comparisons of cooling air flow enthalpy rises, torques required to drive the disc and one-sided moment coefficients for the disc have been made between the experimental and the computational models and agreement was obtained across the range of nondimensional numbers analysed. For the plain disc analyses this agreement was within $2 \%$ to $15 \%$ and was from $6 \%$ to $20 \%$ for the static protrusions on the stator. Results for the roughness on the rotor models corresponded closely with the experimental findings of previous authors. It was also confirmed that increasing roughness on the rotor increased moment coefficient and that increasing roughness from hydrodynamically smooth up to a roughness ratio of 1125 (corresponding to a roughness height of $0.2 \mathrm{~mm}$ ) caused a doubling of torque at all rotational and throughflow Reynolds numbers. The same magnitude of roughness on stator was also found to double the torque experienced by the stationary casing but this only corresponded to a $5 \%$ increase in disc moment coefficient.
\end{abstract}

KEYWORDS: CFD, Rotor-Stator, Cavity, Validation, turbomachinery

\section{NOMENCLATURE}

A area

$\mathrm{C}_{\mathrm{p}} \quad$ specific heat at constant pressure

$\mathrm{C}_{\mathrm{m}} \quad$ one sided moment coefficient, $\mathrm{T}_{\mathrm{q}} / \rho \Omega^{2} \mathrm{~b}^{5}$
$\mathrm{C}_{\mathrm{w}} \quad$ throughflow Reynolds number, $\mathrm{m} / \mu \mathrm{b}$

$\mathrm{C}_{\mu} \quad$ roughness constant (normally 0.09 (Launder and Spalding [1]))

$\mathrm{K}_{\mathrm{s}} \quad$ actual roughness height in meters

$\mathrm{K}_{\mathrm{s}}^{+} \quad$ non-dimensional roughness height

$\mathrm{k} \quad$ turbulence kinetic energy

L appropriate length

$\mathrm{P} \quad$ pressure

$\operatorname{Re}_{\phi} \quad$ rotational Reynolds number, $\rho \Omega b^{2} / \mu$

$\operatorname{Re}_{\phi}{ }^{r} \quad$ modified rotational Reynolds number, $\rho \omega b^{2} / \mu$

$\mathrm{T}$ temperature

$\mathrm{T}_{\mathrm{q}} \quad$ torque

$\Omega \quad$ rotational speed of the disc

$\omega \quad$ core bulk rotational speed of the fluid

$\mathrm{b} \quad$ outer radius of a disc

h enthalpy

$\mathrm{k} \quad$ turbulence kinetic energy

$\mathrm{m} \quad$ mass flow rate

$\mathrm{p} \quad$ pressure

$\mathrm{r}, \mathrm{z}$ radial and axial coordinates

$\mathrm{s} \quad$ axial width of cavity

$\mathrm{u}^{*} \quad \mathrm{C}_{\mu}{ }^{1 / 4} \mathrm{k}^{1 / 2}$

$\mathrm{x} \quad$ non-dimensional radial coordinate, $\mathrm{r} / \mathrm{b}$

$\delta \quad$ boundary layer thickness

$\mu \quad$ dynamic viscosity

$v \quad$ kinematic viscosity

$\rho$ density

$\lambda_{\mathrm{t}} \quad$ turbulent flow parameter, $\mathrm{C}_{\mathrm{w}} /\left(\mathrm{Re}_{\phi}{ }^{0.8}\right)$

1 value at inlet

2 value at exit 


\section{INTRODUCTION}

The efficiency of a gas turbine engines internal cooling system is of great importance to the engineers concerned with their design. Modern gas turbines operate at the very limits of material technology with turbine exit temperatures often reaching $1800 \mathrm{~K}$ [2]. These extremes of temperature can severely reduce the serviceable life of turbine discs and blades if adequate cooling air is not supplied to them [3]. This cooling air is, in the case of the larger aero engine gas turbines, delivered through the internal core of the engine where it passes in between the central shafts and the bores of the compressor discs before travelling over the rotating turbine discs and on to the blades.

These internal cooling flows can consume up to $20 \%$ of the engine's main air throughflow and this value will have to rise still further, or the air system will have to operate more effectively, if turbine entry temperatures are to continue to increase. Gas turbine engines today, as a product of their incremental design, suffer from a 'law of diminishing' returns; huge improvements in individual systems lead to only tiny increases in cycle efficiency. For instance, a massive increase in secondary air system performance (e.g. 10\%) may only increase the overall cycle efficiency by $0.15 \%$ [4]. As a result a full and complete understanding of these internal airflows is essential to increase cooling system effectiveness and hence progress gas-turbine design in the future.

Computational Fluid Dynamic modelling of enclosed shrouded rotor-stator systems with superposed cooling flow supplied at the inner radius, as found in the turbine disc areas, is of key importance if unwanted temperature increases of the cooling air are to be avoided as it travels through the internal core of the engine. These temperature increases; a direct result of the windage heating the air experiences, have a direct effect on specific fuel consumption as they require either increased cooling flow levels or reduced turbine entry temperatures. This is coupled with the fact that the power required to drive the discs within the engine is directly at the expense of the final total power output. The high speed rotational flows found within these environs have been the subject of much study over the past 50 years due to the complexity of some of the flow features encountered. The very thin Ekman-type layers found in close proximity to rotating discs and the radial inflow often associated with stationary casings in the vicinity of rotating discs is often problematic to model due to the necessary grid density and selection of correct turbulence models. This investigation used the computationally inexpensive and commonly used realisable $\mathrm{k}-\varepsilon$ model in order to investigate its suitability in modelling a shrouded rotor-stator wheelspace with axially introduced radial outflow.

Computational Fluid Dynamics is increasingly being used as a fundamental design tool within the gas-turbine and turbomachinery industries and thorough validation of a codes ability to model certain situations is paramount if the produced results are to be trusted. CFD companies carry out their own validation cases in-house, as do many turbomachinery companies; however, unless these results are published they are of limited use to the global engineering community.

This paper aims to provide a thorough validation for CFD models of a shrouded rotor-stator wheelspace with a superposed throughflow of cooling air and adjustable static protrusions.
Models based on an experimental rig at the University of Sussex were used for the validation (for further details see thesis by Coren [5]). These models included plain disc cases, roughened rotor and stator cases as well as static protrusions (in the form of hex headed bolts) placed on the stator at a high radius. A modelling approach was then adopted within the commercially popular Fluent CFD package. This approach analysed a series of test matrices produced from the experimental data which covered a range of engine representative nondimensional flow conditions. The results of the CFD data, in the form of enthalpy rise of the exiting air and torque required to drive the disc, could then be compared and contrasted to the experimental results.

\section{DESCRIPTION OF TEST RIG AND COMPUTATIONAL MODELS}

The experimental setup consists of an encased, shrouded, slightly tapered disc of approximately $0.45 \mathrm{~m}$ in diameter driven by a $50 \mathrm{~kW}$ electric motor via a 5:1 step up gearbox. A flow of cooling air is supplied axially to both sides of the disc; this flow is heated by its interaction with the disc before exiting at the periphery of the case (Figure 1a). The cavities on each side of the disc are separated by a labyrinth seal running around the discs outer circumference, the leakage through which is kept to a minimum by matching conditions on each side of the disc. Further details of the rig and its instrumentation can be found in the thesis by Coren [5]

The torque required to drive the rotating disc is a product of the properties of the fluid surrounding it, the speed at which the disc is driven and the geometry of the system. Torque is measured using an inline torque meter attached to the main drive shaft. Its output can be compared against the enthalpy rise of cooling air using the enthalpy relationship stated in Equation (1), assuming the system is adiabatic. The classical definition of moment coefficient for one side of the disc is shown in Equation (2).

$$
\begin{aligned}
& \Delta \mathrm{h}=\mathrm{mCp}_{2} \mathrm{~T}_{\mathrm{o} 2}-\mathrm{mCp}_{1} \mathrm{~T}_{\mathrm{o} 1}=\mathrm{T}_{\mathrm{q}} \Omega \\
& C_{m}=\frac{T_{q}}{\rho \Omega^{2} b^{5}}
\end{aligned}
$$

Equation (1)

Equation (2)

The experimental data covers a wide range of nondimensional conditions with rotational Reynolds numbers from $3 \times 10^{6}$ to $3 \times 10^{7}$ and throughflow Reynolds numbers from $3 \times 10^{4}$ to $1 \times 10^{5}$ for a gap ratio of 0.1 and an exit gap ratio of 0.038 .

A full uncertainty analysis was carried out on the experimental rig and it was found that the standard variation in recorded torque was $+/-0.346 \mathrm{~N} \mathrm{~m}$ (or $+/-0.678 \mathrm{~N} \mathrm{~m}$ with a 95\% confidence interval) at all rotational and throughflow Reynolds numbers.

Protrusions in the form of $16 \mathrm{~mm}$ hex-head bolts can be attached to the front of the disc or the opposing stationary casing at two different radii corresponding to nondimensional radial locations of 0.88 and 0.60 respectively.

Models were constructed in the Gambit mesh generation program with geometry data extracted from CAD representations of the rig. $2 \mathrm{D}$ and $3 \mathrm{D}$ models were created and validated for the analysis of the plain disc; the base analysis to which all others can be compared. Models were then created to 
analyse both bolts on the stator and bolts on the rotor cases. These cases were then also validated against experimental data taken from the protrusion windage rig at the University of Sussex.

2D axisymmetric models were constructed and meshed with both near wall $(\mathrm{y}+\approx 100)$ and enhanced $(\mathrm{y}+\approx 1)$ wall function meshes, the former generally consisting of approximately 25,000 elements and the latter 70,000. The 3D periodic sector models meshes consisted of approximately 200,000 elements per 10 degrees of sector. Configurations analysed in this report include 18 bolts mounted on the stator at a non dimensional radius of 0.88 , plain disc and stator configurations as well as roughened rotor and stator configurations. For the 2D axisymmetric models both structured quadrilateral and unstructured triangular meshes were utilised. Realisable k- $\varepsilon$ turbulence models were applied to all analyses as it was decided that, while not being the most appropriate turbulence scheme to analyse large angular protrusions in a rotating flow, the $\mathrm{k}-\varepsilon$ model has become somewhat of a standard in many commercial situations so a thorough appraisal of its performance in the rotor-stator cavity in question was deemed necessary.

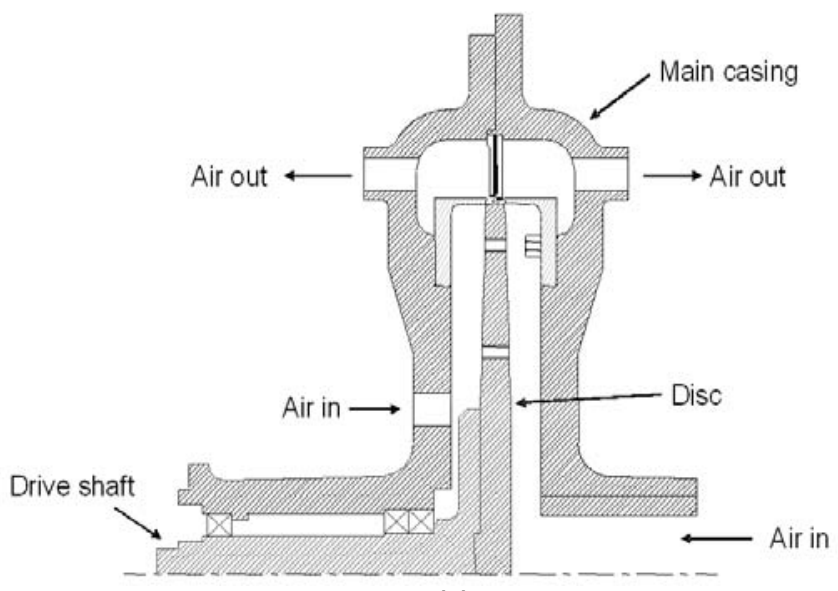

(a)

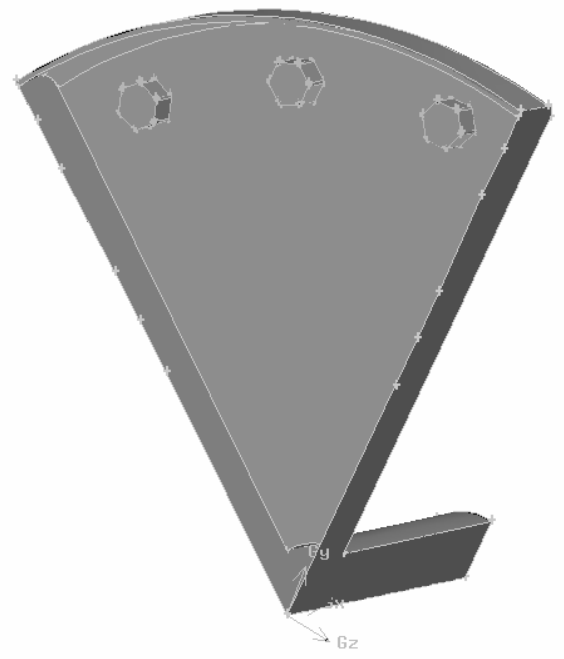

(b)

Figure 1: Illustrations of protrusion windage rig design. Full rig geometry (a) and sectional view of bolts mounted on the stator (b)

\section{BACKGROUND TO PROTRUSION WINDAGE ANALYSIS}

The torque required to drive a smooth, shrouded, rotating disc at constant speed with a superposed cooling flow is not just proportional to the speed at which the disc is driven and its size but is also dependant on the level of throughflow supplied and the physical properties of that flow, i.e. its density and viscosity. An application of the Buckingham Pi theorem to the flow within the rig yields a reduction to two nondimensional groups (assuming geometry is kept constant), these are rotational and throughflow Reynolds number shown in equations (3) and (4) respectively.

$$
\begin{aligned}
& \operatorname{Re}_{\varphi}=\frac{\rho \Omega b^{2}}{2} \\
& C_{w}=\frac{m}{\mu b} \\
& \lambda_{T}=\frac{C_{w}}{\operatorname{Re}_{\varphi} 0.8}
\end{aligned}
$$

Equation (3)

Equation (4)

Equation (5)

It is the ratio of the two nondimensional numbers shown in Equations (3) and (4), known as the turbulent flow parameter, $\lambda_{\mathrm{T}}$ (given in Equation (5)), which is used to determine the approximate flow pattern within the rig (the ratio of rotational and throughflow Reynolds numbers which defines $\lambda_{T}$ is derived from empirical knowledge). The work of Von Karman [6] identified a value of turbulent flow parameter of 0.21 as the transitional point from a rotationally dominated regime to a throughflow dominated one. This has been subsequently confirmed by the work of numerous authors including Nece and Daily [7] and Millward and Robinson [8].

Typical circumferentially averaged flow patterns within the rotor-stator wheel space can be seen in Figure $2 \mathrm{a}$ and $2 \mathrm{~b}$. They show contours of stream function for both a low and a high rotational Reynolds number case. The low Reynolds number case (Figure 2a) would be described as a throughflow dominated flow regime $\left(\lambda_{\mathrm{T}}<0.21\right)$. Radial outflow is not closely entrained onto the rotating disc and is free to penetrate into the core of the cavity. Recirculation down the stationary casing is minimal with the bulk of the flow cleanly exiting via the radially oriented exit slot.

In contrast, in the rotationally dominated scheme (where $\lambda_{\mathrm{T}}$ $>0.21$ ), (Figure 2b), flow is closely entrained onto the disc until its outer radius. Here the flow splits and a large proportion recirculates down the casing before crossing the core and being entrained back onto the disc. In all cases there is a large toroidal vortex which forms as the flow turns through $90^{\circ}$ as it enters the main cavity as labelled in Figure 2 a. 


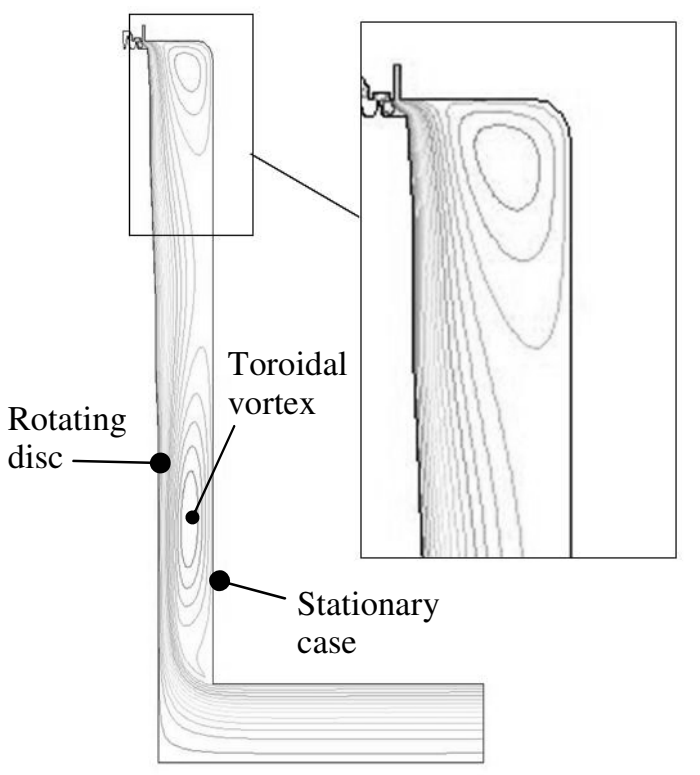

(a)

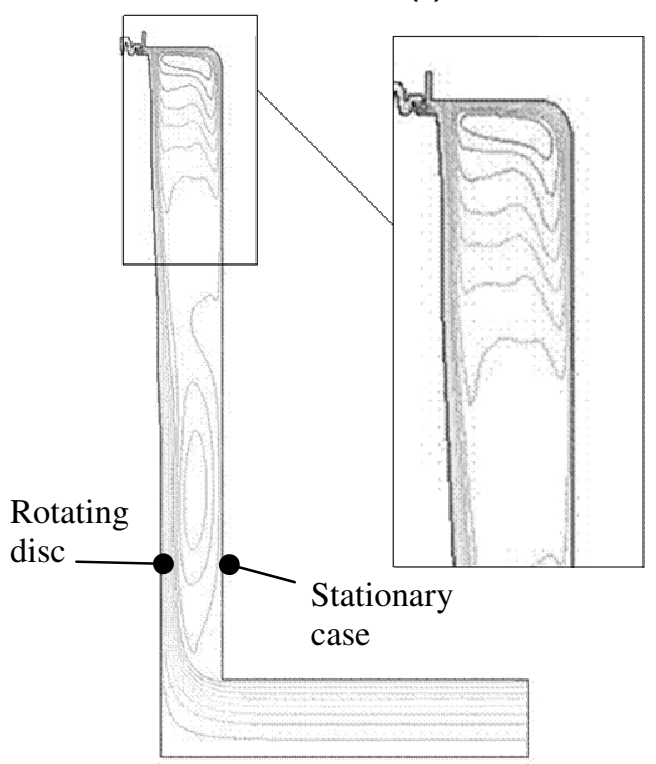

(b)

Figure 2 (a) and (b): CFD Contour plots of stream function for a typical throughflow dominated (a) and rotationally dominated (b) case.

Nece and Daily [7] also identified four possible boundary layer configurations within the rotor-stator wheelspace. They were as follows:

i Laminar flow, merged boundary layers on rotor and stator

ii Laminar flow, separate boundary layers on disc and end wall

iii Turbulent flow, merged boundary layers on rotor and stator

iv Turbulent flow, separate boundary layers on disc and end wall

All modelling in this report falls within the last of these categories as Reynolds numbers are sufficiently high and the unvarying axial gap ratio sufficiently large to keep the flow turbulent and the boundary layers separate. This regime is also representative of the flow patterns found within modern large sized commercial gas-turbine engines.

\section{PLAIN DISC VALIDATION}

In order to establish a base case against which all other cases can be compared the plain disc configuration was analysed first. The plain disc configuration should, based on the assumption that this configuration involves the least flow disturbance, yield the least windage of any of the setups tested and can be used to define the increase in windage for the subsequent tests.

In total thirty two 2D axisymmetric CFD models were created and solved to fully validate the plain disc test case. These runs were grouped into three nominal values of throughflow Reynolds number and cover a spread of rotational Reynolds number ranging from $0.25 \times 10^{7}$ to $2.00 \times 10^{7}$.

Inflow and outflow boundary conditions were defined as pressure inlet and pressure outlet while all walls were kept as adiabatic. Analyses were performed with both low Reynolds Number and standard wall function wall treatment with appropriately different meshes in the near wall region; the low Reynolds number meshes had a first mesh point height of approximately $0.004 \mathrm{~mm}(\mathrm{y}+\approx 1)$ whereas the standard wall function meshes had a first mesh point height of approximately $0.4 \mathrm{~mm}(\mathrm{y}+\approx 100)$. It was hoped that if standard wall functions could adequately achieve a similar accuracy to low Reynolds number wall functions than much time could be saved in both the generation of the mesh and the converging of a solution. Grid independence was confirmed through a grid doubling technique for all meshes.

Plain disc validation graphs for nominal throughflow Reynolds numbers of $0.3 \times 10^{7}, 0.6 \times 10^{7}$ and $0.85 \times 10^{7}$ can be seen in Figures 3, 4 and 5 respectively. Figure 3 shows a plot of one sided moment coefficient plotted against rotational Reynolds number for a series of modelling runs. From the graph it can be observed that the variation in moment coefficient between both near wall and standard wall function CFD models and the experimental data is minimal for values of rotational Reynolds number greater than $0.5 \times 10^{7}$. Below this Reynolds number there is a divergence between CFD and experimental data (although this divergence corresponds to the lower rotational speed runs where torque and temperature rises are small, often close to the resolution of the instrumentation).

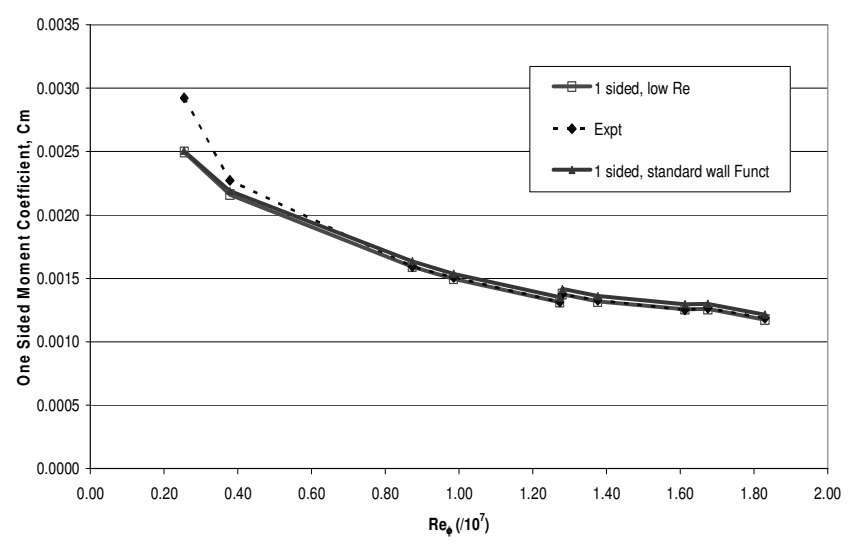

Figure 3: CFD predicted and experimentally measured variation of one-sided moment coefficient vs rotational Reynolds number for a throughflow Reynolds number, $\mathrm{C}_{\mathrm{w}}$, of $0.3 \times 10^{5}$. 


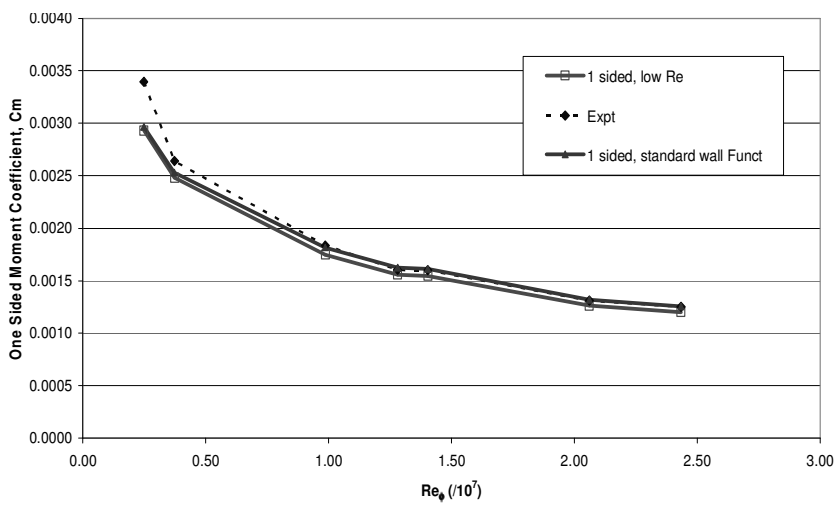

Figure 4: CFD predicted and experimentally measured variation of one-sided moment coefficient vs rotational Reynolds number for a throughflow Reynolds number, $\mathrm{C}_{\mathrm{w}}$, of $0.6 \times 10^{5}$.

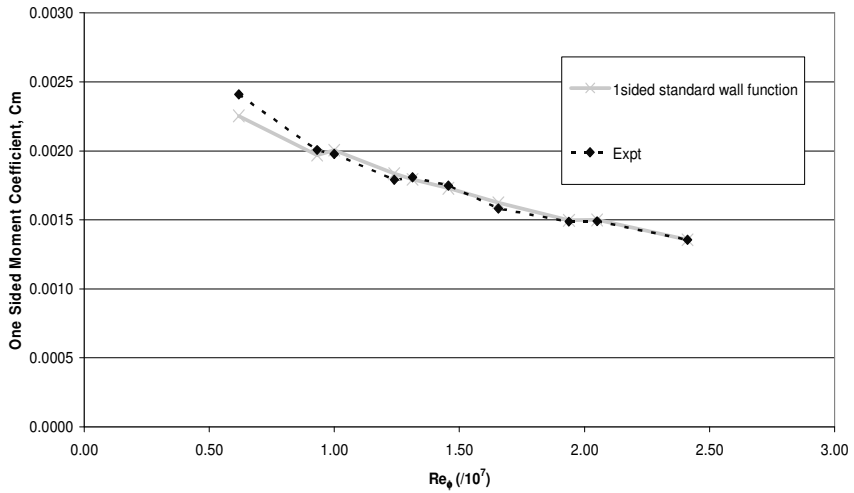

Figure 5: CFD predicted and experimentally measured variation of one-sided moment coefficient vs rotational Reynolds number for a throughflow Reynolds number, $\mathrm{C}_{\mathrm{w}}$, of $0.85 \times 10^{5}$.

Similar trends can be observed in Figure 4 and 5 which show one-sided moment coefficient plotted against rotational Reynolds number for throughflow Reynolds numbers of $0.6 \times 10^{5}$ and $0.85 \times 10^{5}$ respectively. Kinks can be observed in all three graphs, these are caused by the fact that the CFD models were exact replicas of the experimental runs carried out on the rig to enable a later comparison of Laser Doppler Anemometry data and computationally predicted velocities. The experimental data contained kinks due to difficulties in attaining exact non-dimensional conditions on the rig.

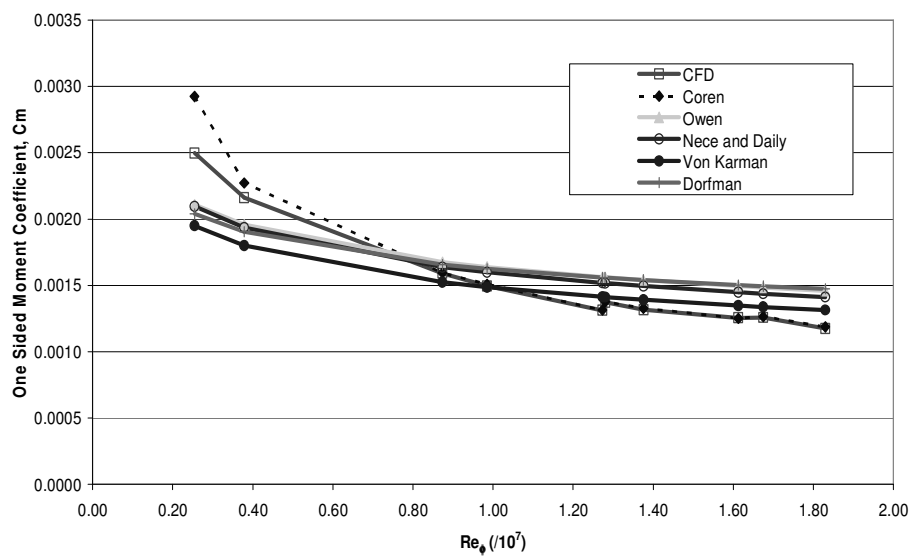

Figure 6: CFD predicted and previously measured experimental variation of one-sided moment coefficient vs rotational Reynolds number for a nominal throughflow Reynolds number, $\mathrm{C}_{\mathrm{w}}$, of $0.3 \times 10^{5}$.
Earlier experimental data has also been examined and compared against the CFD models. The work of Dorfman [9], von Kármán [6], Owen [10] and Nece and Daily [7] was compared with the CFD data and is shown in Figure 6.

It can be seen that the other authors' correlations under predict moment coefficient at low Rotational Reynolds numbers when compared to the experimental data and the CFD. This trend is reversed at high rotational Reynolds numbers with the other authors' correlations over estimating recorded moment coefficient. This can be partially explained by the fact that experiments conducted by Owen, Nece and Daily, Von Karmen and Dorfman were carried out at rotational Reynolds numbers of lesser magnitude that those used by Coren. Their correlations have then been extended into the non-dimensional range required for this investigation.

\section{ROUGHNESS INVESTIGATION}

Various different surface roughnesses were analysed on both the rotor and the stator across a range of rotational Reynolds numbers during the course of the investigation. The effect on output temperature and torque was recorded and contrasted to that of the corresponding plain disc case. As one would expect, increasing roughness on the rotor leads to an increased exit air total temperature rise at all rotational Reynolds numbers, far more so than alterations to gap ratio according to Nece and Daily [7]. However, increasing roughness on the stator was found to have a much lesser effect.

Three roughness regimes have been identified through previous experimental analysis of rough surfaces. These are: hydrodynamically smooth, transitional and fully rough. The regime a rough surface falls under is not just a product of its roughness height but also of the fluid surrounding the surface. A non-dimensional roughness height, $\mathrm{K}_{\mathrm{s}}^{+}$(Equation (6)), is used to classify the surface under investigation into one of the three regimes.

$\mathrm{K}_{\mathrm{s}}^{+}=\rho \mathrm{K}_{\mathrm{s}} \mathrm{u}^{* / \mu}$

Equation (6)

According to Cebeci and Bradshaw [11] the roughness regime can then be deduced by the fact that:
$\mathrm{K}_{\mathrm{s}}^{+} \leq 2.25$
Hydrodynamically smooth
$2.25<\mathrm{K}_{\mathrm{s}}^{+} \leq 90$
Transitional
$\mathrm{K}_{\mathrm{s}}^{+}>90$
Fully rough

$\mathrm{K}_{\mathrm{s}}^{+}$values for our models range from 0.11 for smooth, low pressure, low turbulence kinetic energy models up to 200 for rough, high pressure, high turbulence kinetic energy models, thereby covering a full range of non-dimensional roughness factors from hydrodynamically smooth to fully rough. Roughness was modelled in the Fluent program by imposing a uniformly sized surface texture across the relevant model boundary (either the disc or the stationary casing).

Plotting the data for the roughened stationary casing gives the variation of moment coefficient with rotational Reynolds number as shown in Figure 7. It can be seen from this figure that moment coefficient falls with increasing rotational Reynolds number and rises with increasing roughness heights. Also, note how there is no discernable difference between the plain disc case and that with a roughness ratio of 225,000 . A ten percent increase in moment coefficient compared to the plain disc occurs with a roughness ratio of approximately 
37,500 , corresponding to a roughness height of $6 \mu \mathrm{m}$, almost four times rougher than the typical value of $2 \mu \mathrm{m}$ currently found on gas turbine compressor and turbine discs. However, stationary cast components are often considerably rougher.

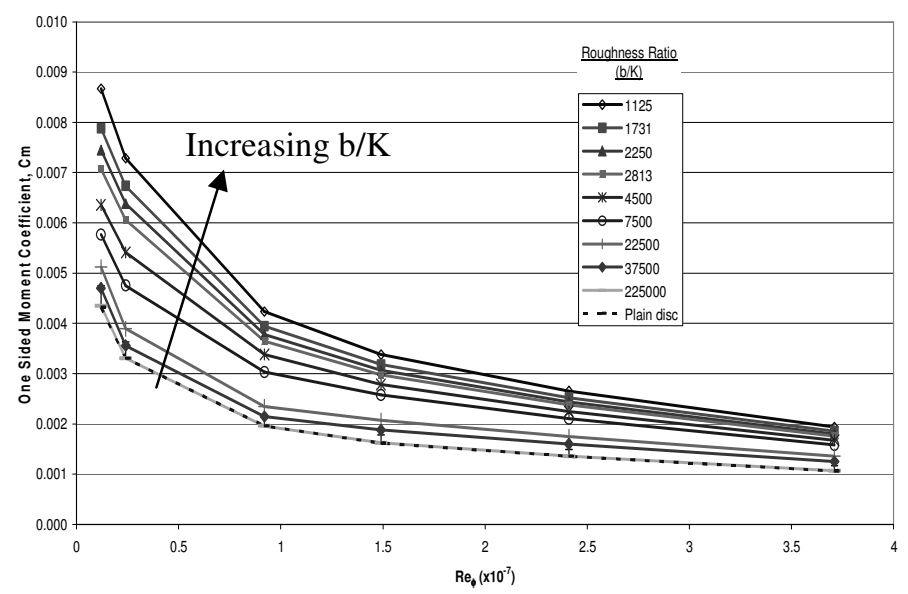

Figure 7: Graph showing CFD predicted variation of one sided moment coefficient vs rotational Reynolds number for several different surface roughnesses's on the rotor ranging from $1125<$ $\mathrm{b} / \mathrm{K}<225000$ for a throughflow Reynolds number, $\mathrm{C}_{\mathrm{w}}$, of $0.9 \times 10^{5}$.

Increasing roughness from totally smooth (infinite roughness ratio) up to a roughness height of $0.2 \mathrm{~mm}$ (roughness ratio of 1125) increases moment coefficient by an approximate factor of 2 at all rotational Reynolds numbers. This relationship is in agreement with the data produced by Daily and Nece 7] who, for fully turbulent flow, recorded a doubling of moment coefficient between the plain disc case and a roughness ratio of 1000 (albeit at a lower range of rotational Reynolds number from $4 \times 10^{3}$ to $4 \times 10^{6}$ ).

Roughness on the stator was also examined and was found to have very little effect on disc torque when compared to that of roughness on the rotor. Increasing roughness from hydrodynamically smooth up to a roughness ratio of $1125 \mathrm{did}$ not noticeably increase the air enthalpy rise in the throughflow dominated regime and only by about $5 \%$ in the rotationally dominated scheme [Figure 8]. An equivalent reduction in rotational velocity of the core flow at higher radii was also noted [Figure 9]. This is unexpected as one would assume that an increased stator roughness would significantly reduce the rotational speed of the core flow and hence increase the shear between the core flow and the disc. One would, however, expect a roughened stator to have little effect in a throughflow dominated regime where core rotation is minimal.

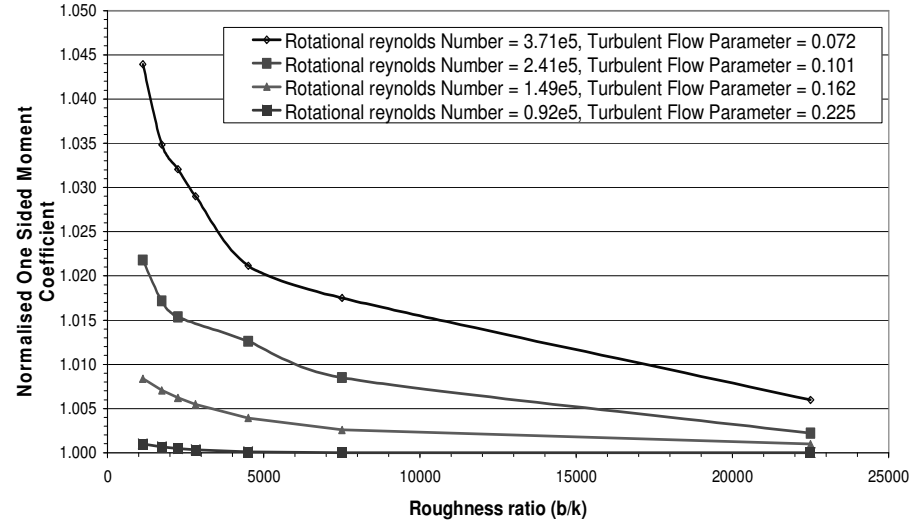

Figure 8: Variation of Normalised Disc Moment Coefficient with Roughness Ratio for Various Rotational Reynolds Numbers at a Nominal Throughflow Reynolds Number, Cw, of $0.88 \times 10^{5}$.

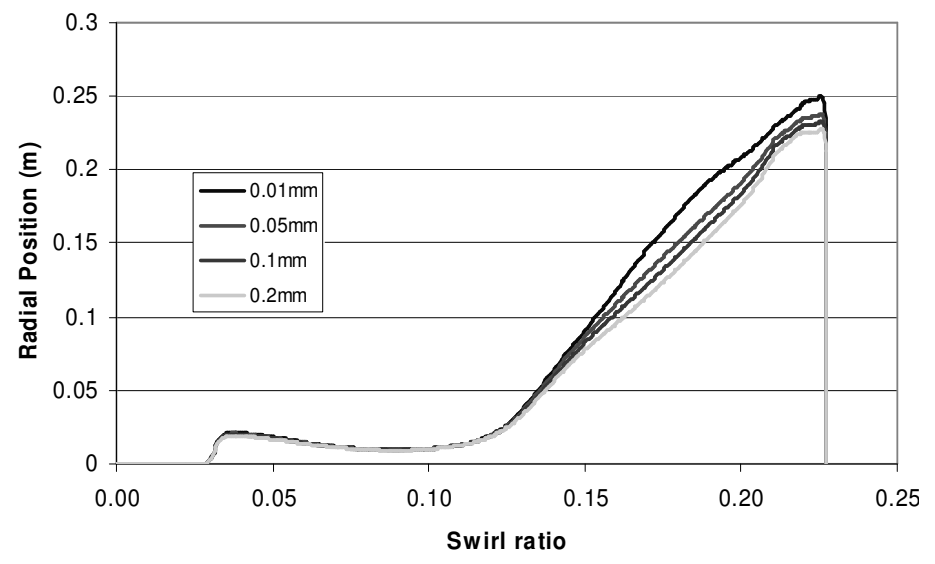

Figure 9: Development of Swirl Ratio with Increasing Radial Position for Four Different Stator Roughness Heights at a Nominal Throughflow Reynolds Number, Cw, of $0.88 \times 10^{5}$.

It was found that torque on the stator did increase with stator roughness [see Figure 10] as you would assume but this effect did not extend to the disc torque. One possible explanation for this is that the boundary layer thickness on the stator was sufficiently large to prevent the roughness from penetrating into the region of bulk rotation in the wheelspace. This would mean that the rotating core region would be unaffected by the stator roughness and hence no effect would be noticed on the rotor torque. This can be confirmed by calculating the boundary layer thickness over a stationary disc in a rotating environment using Equation (7) proposed by Owen [10]. This gives a boundary layer thickness of approximately $2 \mathrm{~mm}$

$\delta / \mathrm{r}=0.0983\left(\mathrm{x}^{2} \operatorname{Re}_{\varphi}^{\mathrm{r}}\right)^{-1 / 5}$

Equation (7) 


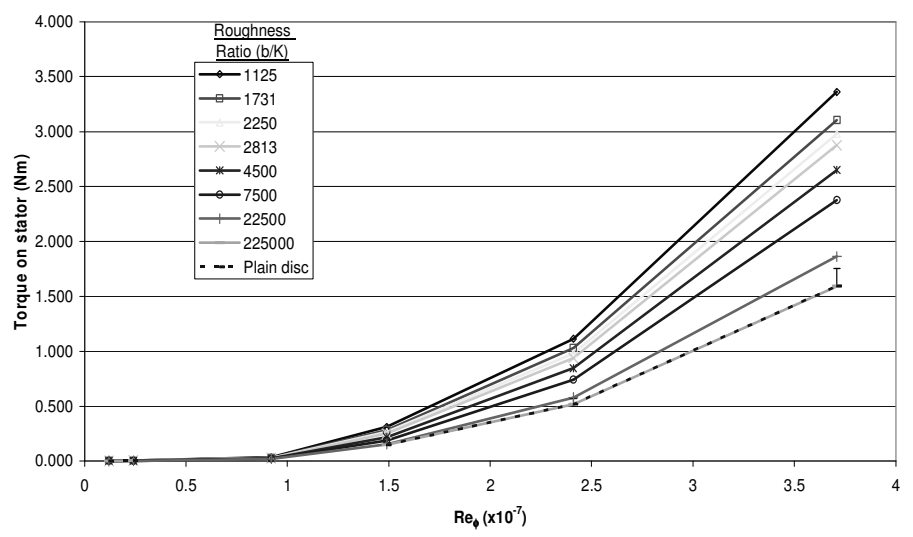

Figure 10: Graph showing CFD predicted variation of stator torque vs rotational Reynolds number for several different stator surface roughnesses's ranging from $1125<b / K<225000$ for a throughflow Reynolds number, $\mathrm{C}_{\mathrm{w}}$, of $0.9 \times 10^{5}$.

\section{PROTRUSIONS ON STATOR}

Once the plain disc base case had been run and validated the investigation into static protrusions could be carried out. This investigated 18 hex-headed bolts mounted on the stationary casing. The mesh contained approximately 500,000 elements in the $20^{\circ}$ sector and used standard wall functions in the near wall region giving $\mathrm{y}^{+}$values of around 100. A range of models were then constructed and validated against the available experimental data.

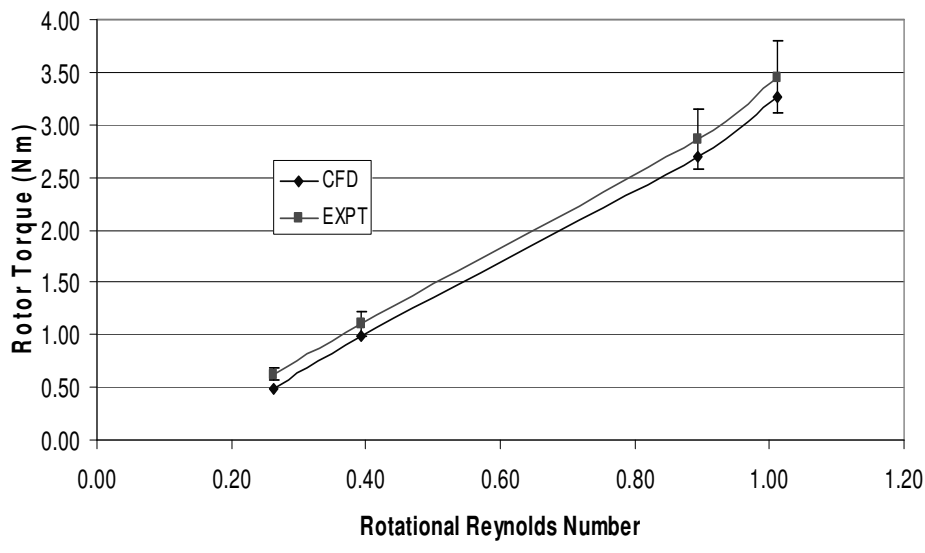

Figure 11: Graph showing CFD predicted and experimentally measured rotor torque vs rotational Reynolds number for 18 bolts mounted on the stator for a throughflow Reynolds number, $\mathrm{C}_{\mathrm{w}}$, of $0.3 \times 10^{5}$.

Figure 11 shows reasonable trend agreement between the experimental and CFD data across the range of rotational Reynolds numbers analysed. Differences between CFD and experimental results are limited to $20 \%$ at low rotational Reynolds numbers and to $6 \%$ at high Rotational numbers. There is a clear downward shift in the CFD results across the range of rotational Reynolds numbers tested, possibly due the realisable $\mathrm{k}-\varepsilon$ turbulence models inability to capture the losses caused the protruding bolt heads. Future investigations will aim to confirm or deny this through the use of alternative turbulence models including Large Eddy Simulation (LES).

The effect of the turbulent flow parameter, $\lambda_{\mathrm{T}}$, can be observed in Figure 12 which shows the path lines of the cooling flow local to the protrusions on the stator. The graduation between rotational domination and throughflow domination can clearly be seen to evolve in Figures 12a 12b and 12c respectively. As the throughflow begins to dominate (Figure 12c) it can be seen how the wake shed from the bolt takes up a circumferential path, leading it to interact with the following bolt. This process, known as slipstreaming, is ultimately believed to lead to a reduction in torque experienced by the stator as the number of bolts is increased. The work of Zimmermann et al. [12] discovered that torque increases with the number of bolts and that shielding a row of bolts with an axisymmetric shroud reduced windage. As the number of bolts in a ring increases there will be a point where windage must start to fall because the bolts are close enough together to act as if they were a constant ring. Therefore increasing bolt number above this value will cause a reduction in windage. Future work aims to identify the number of bolts of a given size and at a specified radius which give maximum windage losses.

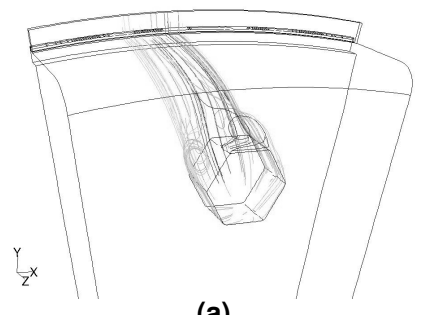

(a)

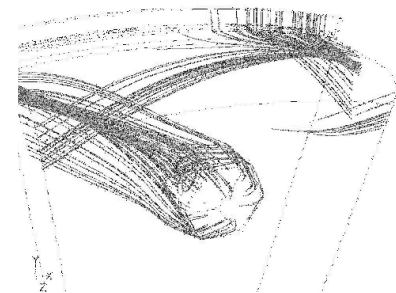

(b)

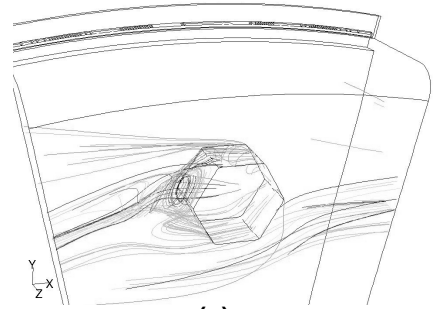

(c)

Figure 12: Visualisation of cooling flow pathlines local to the static protrusion for a throughflow dominated regime, $\lambda_{T} \approx 0.5$ (a), a transitional regime, $\lambda_{\mathrm{T}} \approx 0.21$ (b) and a rotationally dominated regime, $\lambda_{T} \approx 0.1$ (c).

\section{CONCLUSIONS}

This paper has presented a comparison between experimental data and numerical predictions for the case of a shrouded rotor-stator wheelspace with a superposed radial outflow and a series of torque increasing features on both the rotor and the stator. This combination of experimental data and agreeing numerical predictions are of great importance to turbomachinery design as they give a quantitative and qualitative estimate of the expected increase in cooling air enthalpy rise caused by roughness on the rotor or stator and by protrusions on the stator. Understanding the causes of this enthalpy rise is of key importance if more efficient and effective internal air systems are to be designed in the future.

The work presented in this paper assesses ability of a CFD code to model the flow patterns, torques and temperature rises associated with the shrouded rotor-stator wheel-space with superposed cooling flow. The analyses were carried out in conditions that are typical of an industrial setting utilising a popular commercial CFD code with a well known turbulence 
model. Two key flow regimes were confirmed to occur, one rotationally dominated and the other throughflow dominated. A value of turbulent flow parameter of 0.21 was confirmed to be the demarcation point between these two regimes as found by Owen [10].

Plain disc, rough disc, rough stator and bolts on stator CFD models were created and analysed and agreement was obtained between the computational and experimental results (both modern and historical), especially at higher rotational Reynolds numbers where torques and associated temperature rises are large. For the plain disc models both enhanced and standard wall functions gave acceptable results which were within $2 \%$ of the experimental data for rotational Reynolds numbers greater than $5 \times 10^{6}$ and within $15 \%$ for Rotational Reynolds numbers below $5 \times 10^{6}$ (where torques and temperature rises are minimal).

The roughened rotor models also provided agreement with available experimental data with the general trend being that an increase in roughness from hydrodynamically smooth up to a sandpaper type roughness caused a doubling of moment coefficient across the range of rotational and throughflow Reynolds numbers. Roughness on the stator was found to have a much lesser effect on the disc torque although a not insignificant torque increase of up to $5 \%$ was observed in the highly rotationally dominated models. This corresponded to an equivalent retardation in core rotational velocity, hence causing an increase in the shear between the rotating disc and the slower rotating fluid in the wheelspace.

Models for 18 bolts on the stator were found to give less conclusive agreement but were still within an acceptable level of accuracy of between $6 \%$ in the rotationally dominated regime and $20 \%$ in the throughflow dominated regime (where temperature rises are proportionally smaller). The effect of the turbulent flow parameter was also found to drastically alter the flow pattern within the wheelspace, especially local to the bolt where the relative angle that the fluid meets the bolt was found to be dependant on the flow regime within the wheelspace.

\section{ACKNOWLEDGMENTS}

The authors would like to thank Rolls-Royce plc for their continued support of the Thermo-Fluid Mechanics Research Centre at the University of Sussex, which has made this research project possible. In addition the authors wish to express their thanks to the European Union and participating companies in the ICAS-GT2 (Flow and Heat Transfer in the Rotating Cooling Air Systems of Gas Turbines 2) programme of research, funded by the 5th Framework of the GROWTH programme of the European Union.

\section{REFERENCES}

[1] B. E. Launder and D. B. Spalding, 1974 'The Numerical Computation of Turbulent Flows' Computer Methods in Applied Mechanics and Engineering, pp.269-289.

[2] Rolls-Royce plc, 2005 'The Jet Engine', ISBN: 0902121235.

[3] P. D. Smout, 2001 'ICAS-GT - EU Research into Gas Turbine Internal Air System Performance' Air and Space Europe, Vol 3, number 374.

[4] A. Foley, 2001 'On the Performance of Gas Turbine Secondary Air Systems' ASME IGTI Congress, paper number 2001-GT-199.
[5] D. D. Coren, 2007 'Bolt Windage in Gas Turbines' University of Sussex Thesis.

[6] T. von Kármán, 1921 'Technical Memorandum on Laminar and Turbulent Friction' NACA Report No. 1092.

[7] R. E. Nece and J. W. Daily, 1960 'Roughness Effects on Frictional Resistance of Enclosed Rotating Discs' Trans. ASME, series D, Journal of Basic Engineering. pp.553-560.

[8] J. A. Millward and P.H. Robinson, 1989 'Experimental Investigation into the Effects of Rotating and Static Bolts on Both Windage Heating and Local Heat Transfer Coefficients in a Rotor/Stator Cavity' Gas Turbine and Aeroengine Congress, paper number 89-GT-196.

[9] L.A Dorfman, 1963 'Hydrodynamic resistance and the heat loss of rotating solids' Oliver and Boyd, Edinburgh.

[10] J.M. Owen, R.H. Rogers, 1989 'Flow and Heat Transfer in Rotating-Disc Systems, Volume 1: Rotor-Stator Systems' Research Studies Press, Wiley, New York.

[11] T. Cebeci and P. Bradshaw, 1977 'Momentum Transfer in Boundary Layers' Hemisphere Publishing Corporation, New York.

[12] H. Zimmermann, A. Firsching, G. H. Dibelius, and M. Ziemann, 1986 'Friction losses and flow distribution for rotating disks with shielded and protruding bolts,' ASME Trans. J. Eng. Gas Turbines Power, vol. 108, pp.547-552. 